\title{
Rapid and sensitive methodology for determination of ethyl carbamate in fortified wines using microextraction by packed sorbent and gas chromatography with mass spectrometric detection ${ }^{\text {is }}$
}

\author{
João M. Leça ${ }^{a}$, Vanda Pereira ${ }^{a, b, *}$, Ana C. Pereira ${ }^{c}$, José C. Marquesa,b \\ a Centre of Exact Sciences and Engineering, University of Madeira, Campus da Penteada, 9000-390 Funchal, Portugal \\ ${ }^{\mathrm{b}}$ Institute of Nanostructures, Nanomodelling and Nanofabrication (I3N), University of Aveiro, Aveiro, Portugal \\ c CIEPQPF, Department of Chemical Engineering, University of Coimbra, Pólo II - Rua Sílvio Lima, 3030-790 Coimbra, Portugal
}

\section{H I G H L I G H T S}

- MEPS was first used to quantify ethyl carbamate in fortified wines.

- The extraction was optimized (DoE) to $300 \mu \mathrm{L}$ of sample and $100 \mu \mathrm{L}$ of dichloromethane.

- Good linearity $\left(R^{2}=0.9999\right)$ and low LOQ $\left(4.5 \mu \mathrm{g} \mathrm{L}^{-1}\right)$ were obtained.

- The method applicability was demonstrated by the analysis of 16 fortified wines.

- MEPS ensured efficiency and effectiveness without using sophisticated equipment.

\section{A R T I C L E I N F O}

\section{Article history:}

Received 7 October 2013

Received in revised form 9 December 2013

Accepted 16 December 2013

Available online 21 December 2013

\section{Keywords:}

Ethyl carbamate

Wines

Microextraction by packed sorbent Gas chromatography-mass spectrometric detection

\section{G R A P H I C A L A B S T R A C T}

\begin{abstract}
A B S T R A C T
This work presents a new methodology to quantify ethyl carbamate (EC) in fortified wines. The presented approach combines the microextraction by packed sorbent (MEPS), using a hand-held automated analytical syringe, with one-dimensional gas chromatography coupled with mass spectrometry detection (GC-MS). The performance of different MEPS sorbent materials was tested, namely SIL, C2, C8, C18, and M1. Also, several extraction solvents and the matrix effect were evaluated. Experimental data showed that C8 and dichloromethane were the best sorbent/solvent pair to extract EC. Concerning solvent and sample volumes optimization used in MEPS extraction an experimental design (DoE) was carried out. The best extraction yield was achieved passing $300 \mu \mathrm{L}$ of sample and $100 \mu \mathrm{L}$ of dichloromethane. The method validation was performed using a matrix-matched calibration using both sweet and dry fortified wines, to minimize the matrix effect. The proposed methodology presented good linearity $\left(R^{2}=0.9999\right)$ and high sensitivity, with quite low limits of detection (LOD) and quantification (LOQ), $1.5 \mu \mathrm{gL}^{-1}$ and $4.5 \mu \mathrm{gL}^{-1}$, respectively. The recoveries varied between $97 \%$ and $106 \%$, while the method precision (repeatability and reproducibility) was lower than $7 \%$. The applicability of the methodology was confirmed through the analysis of 16 fortified wines, with values ranging between 7.3 and $206 \mu \mathrm{g} \mathrm{L}^{-1}$. All chromatograms showed good peak resolution, confirming its selectivity. The developed MEPS/GC-MS methodology arises
\end{abstract}

Abbreviations: EC, ethyl carbamate; MEPS, microextraction by packed sorbent; GC-MS, gas chromatography-mass spectrometry; FW, fortified wine; DoE, experimental design; BIN, barrel insert needle; IS, internal standard; ME, matrix effect; LOD, limit of detection; LOQ limit of quantification.

论 Selected paper presented at In Vino 2013 - Reims, France from 3 to 5 July 2013.

* Corresponding author at: Centre of Exact Sciences and Engineering, University of Madeira, Campus da Penteada, $9000-390$ Funchal, Portugal. Tel.: +351 291705122.

E-mail addresses: vpereira@uma.pt, nulita.pereira@gmail.com (V. Pereira). 
as an important tool to quantify EC in fortified wines, combining efficiency and effectiveness, with simpler, faster and affordable analytical procedures that provide great sensitivity without using sophisticated and expensive equipment.

(c) 2013 Elsevier B.V. All rights reserved.

\section{Introduction}

Ethyl carbamate (EC), also known as urethane, is the ester of carbamic acid $\left(\mathrm{H}_{2} \mathrm{NCOOC}_{2} \mathrm{H}_{5}\right)$. It is known as a toxic compound and was re-classified in 2007 by the International Agency of Research on Cancer (IARC) as a probably carcinogenic to humans (Group 2A) [1].

EC is formed in small amounts in fermented or heated food, namely in alcoholic beverages, including fortified wines. The EC formation in these foodstuffs is usually associated with storage time and temperature [2]. This compound results from the reaction between ethanol and nitrogenous compounds like urea, citruline, hydrocyanic acid and $\mathrm{N}$-carbamyl compounds [3-5]. One of the most common pathways proposed to explain the development of EC in acid media consists in the reaction of urea with ethanol [6]. The kinetics of this reaction is greatly enhanced by the temperature increase $[7,8]$. Urea and citruline can be detected in wine and are both derived from the arginine metabolism during the fermentative processes $[6,8,9]$. Another precursor of EC referenced in the bibliography is hydrogen cyanide derived from cyanogenic glycosides, produced by several plant species, including Vitis vinifera L. [10,11]. The formation of EC via cyanide is mostly originated through procedures that include thermal treatments like distillation or baking [6].

The toxicological concerns led Canada to establish by the first time, in 1985, legislation regulating the EC limit values in alcoholic beverages, namely in fortified wines to $100 \mu \mathrm{g} \mathrm{L}^{-1}$. Other legal limits were also imposed: $30 \mu \mathrm{g} \mathrm{L}^{-1}$ for table wines, $150 \mu \mathrm{g} \mathrm{L}^{-1}$ for distilled spirits, $200 \mu \mathrm{gL}^{-1}$ for sake and $400 \mu \mathrm{g} \mathrm{L}^{-1}$ for fruit brandies and liqueurs $[6,12]$. In Europe, only Czech Republic follows the Canadian legislation for fortified wine [12].

The concerns raised by the toxicological aspects of EC together with the low concentration levels $\left(\mu \mathrm{g} \mathrm{L}^{-1}\right)$ found in wines, as well as the occurrence of interferences on detection, has motivated several researchers to develop new methods to determine it in wines. Several extraction and chromatographic techniques have been used, including continuous liquid-liquid extraction (LLE) with Soxhlet apparatus [13], derivatization with 9-xanthydrol followed by high performance liquid chromatography (HPLC) with fluorescence detection [14] and even LLE after derivatization, followed by gas chromatography coupled with mass spectrometry detection (GC-MS) [15]. On the other hand, the reference method set by the International Organization of Vine and Wine (OIV) [17] uses solid phase extraction (SPE) preceding GC-MS quantification [16]. Other methods also make use of SPE, but use gas chromatography with mass spectrometry (MDGC/MS) [18] and liquid chromatography with tandem mass spectrometry (LC-MS/MS) for detection [19]. Most of the methodologies found in the literature to quantify EC use gas chromatography, using LLE [13,20,21] and SPE [16-18,22,23] as extraction techniques. Nevertheless, several efforts have also been done to develop new methodologies to determine EC without using long procedures and hard-working analyses, combining precision to high sensitivity. In this regard, headspace solid phase microextraction (HS-SPME) has been gaining great highlighting [24-26] and alternative methodologies has been proposed using the most recent identification and quantification technology, such as gas chromatography with tandem mass spectrometry detection (GC-MS/MS) [26] and two-dimensional gas chromatography with time-of-flight mass spectrometry (GC $\times$ GC-ToFMS) [25]. Liao et al. [27] also used an emergent extraction technique, based on ultrasound-assisted emulsification-microextraction (USAEME) to extract EC in alcoholic beverages, but using gas chromatography coupled to triple quadrupole mass spectrometry. However, this kind of technologies is still not accessible to many laboratories.

Recently, microextraction by packed sorbent (MEPS) has also becoming emergent, arising as a feasible and easy-to-use extraction technique. MEPS derives from the miniaturization of the conventional SPE, but with additional advantages: uses small sample and solvent volumes (microliters) and consequently reduces the environmental impact, increases the analysis sensitivity and enables the direct injection into the LC or GC instruments. The small cartridge can be packed or coated with different silica-based polymers: SIL (unmodified silica), C2 (ethyl), C8 (octyl), C18 (octadecyl) and M1 (80\% C8 and 20\% SCX - strong cation exchanger using sulfonic acid bonded silica), providing selective and suitable sampling conditions [28]. The MEPS technique has been used to determine other compounds of interest for the alcoholic beverages industry [29-31]; however, as far as we know, it has never been applied for the analytical determination of EC.

The aim of this study was the development of a fast, simple and sensitive methodology to quantify EC in fortified wines using MEPS extraction combined with one-dimensional GC-MS equipment, accessible to most laboratories.

\section{Materials and methods}

\subsection{Chemicals and samples}

Ethyl carbamate (EC) was purchased from Acros Organics (Geel, Belgium), while butyl carbamate (BC), used as an internal standard (IS), was obtained from Sigma-Aldrich (Steinheim, Germany). All standards had a purity grade of more than $97 \%$. Absolute ethanol, $>99.8 \%$ (GC), was purchased from Sigma-Aldrich (Steinheim, Germany), tartaric acid and methanol from Panreac (Barcelona, Spain) while acetonitrile, ethyl acetate and dichloromethane were from Fisher Scientific (Leicestershire, UK). Ultra-pure water (18 M $\Omega$ ) was prepared by the Simplicity ${ }^{\circledR}$ UV ultrapure water (type 1) apparatus from Millipore (Milford, MA, USA).

EC and BC stock solutions of $1 \mathrm{~g} \mathrm{~L}^{-1}$ were prepared by dissolving appropriate amounts of each compound in ultra-pure water. In order to obtain the matrix-matched calibration solutions, suitable dilutions of the stock solutions were prepared with ultra-pure water, to obtain the intermediate solutions of $50 \mathrm{mg} \mathrm{L}^{-1}$ in EC and $10 \mathrm{mg} \mathrm{L}^{-1}$ in $\mathrm{BC}$, which were then used to spike dry and sweet fortified young wines. Each calibration point was extracted in triplicate, within the validation range $5-400 \mu \mathrm{g} \mathrm{L}^{-1}$.

The sweet and dry fortified wines used to perform the matrixmatched calibrations were obtained from V. vinifera L. white varieties and were absent of quantifiable amounts of EC and BC. Regarding the application sample set, 16 fortified wines, aged up to 36 years old and with ethanol contents between 18\% and $20 \%$ were analyzed using the developed methodology.

\subsection{Apparatus and chromatographic conditions}

$\mathrm{eVol}^{\circledR}{ }^{\circledR} \mathrm{MEPS}^{\mathrm{TM}}$ hand-held automated analytical syringe (SGE Analytical Science, Australia) of $500 \mu \mathrm{L}$ was used and MEPS barrel 
insert needles (BINs, $8 \mu \mathrm{L}, 45 \mu \mathrm{m}$ particle size and $60 \AA ̊$ pore size), containing $4 \mathrm{mg}$ of different packing polymers (SIL, C2, C8, C18 and M1) were tested to optimize the extraction.

All analyses were carried out using a GC-MS system, the TRACE GC Ultra gas chromatograph equipped with the ISQ single quadrupole and the TriPlus autosampler (liquid mode) from Thermo Scientific (Hudson, NH, USA). The column was a DB-WAX $60 \mathrm{~m} \times 0.250 \mathrm{~mm}$ with $0.50 \mu \mathrm{m}$ film thickness from Agilent $\mathrm{J} \& \mathrm{~W}$ (Folsom, CA, USA). The carrier gas was helium at a constant flow rate of $1 \mathrm{~mL} \mathrm{~min}^{-1}$. The injector port that was kept at $230^{\circ} \mathrm{C}$, in splitless mode, while the transfer line and the ion source were maintained at $230^{\circ} \mathrm{C}$ and $240^{\circ} \mathrm{C}$, respectively. The oven temperature program started at $40^{\circ} \mathrm{C}$, hold $1 \mathrm{~min}$, increased to $180^{\circ} \mathrm{C}$ at $20^{\circ} \mathrm{C} \mathrm{min}^{-1}$ and hold for $15 \mathrm{~min}$, with a total GC run time of $23 \mathrm{~min}$.

The mass spectrometer was operated in electron impact (EI) mode at $70 \mathrm{eV}$. Initially, some tests with standards and samples were performed with chromatograms obtained in total ion count (TIC), in the range $m / z 30-400$, to ensure the retention time of EC and BC. Then, selective ion monitoring (SIM) of the three characteristic ions $m / z 62,74$ and 89 of both compounds was tested in order to ensure good resolution. Also, to increase the sensitivity and to meet quantification purposes, further analyses were performed using the ion $m / z 62$.

\subsection{MEPS optimization}

As aforementioned, retention times of $\mathrm{EC}$ and $\mathrm{BC}$ were previously determined using individual standards dissolved in dichloromethane, with chromatograms recorded in TIC. Several solvents were individually analyzed in order to check the absence of EC, specifically ethanol, methanol, acetone, ethyl acetate, acetonitrile and dichloromethane, through direct injection into GC-MS. Additionally, several commercially available sorbent materials (SIL, $\mathrm{C} 2, \mathrm{C} 8, \mathrm{C} 18$ and M1) were tested and the extraction was performed with all EC free solvents. Meantime, the best extraction solvent was also chosen. The standard solution used for these tests was set to $100 \mu \mathrm{g} \mathrm{L}^{-1}$ of EC (limit imposed by Canada) spiked with $24 \mu \mathrm{g} \mathrm{L}^{-1}$ of BC (internal standard). After choosing the ideal BIN and extraction solvent, the MEPS procedure was then optimized performing an experimental design (DoE). This is an experimental strategy in which factors (experimental variables that can affect the response) are varied together, instead of one at a time. The experiments carried out are designed economically and efficiently, while individual and combined factors are evaluated [32]. In this study, the analyzed factors were the sample and solvent volumes to be used in the extraction procedure. As response variable, the GC-MS data were used, namely to evaluate the factors - levels combination that ensure its maximization. For each factor, three levels were examined, varying from 200 to $1000 \mu \mathrm{L}$ and 100 to $350 \mu \mathrm{L}$ to sample and solvent volumes, respectively. The plan to carry out the experiments as well as the data analysis was computed using Matlab software (version 7.6, the Mathworks Inc.).

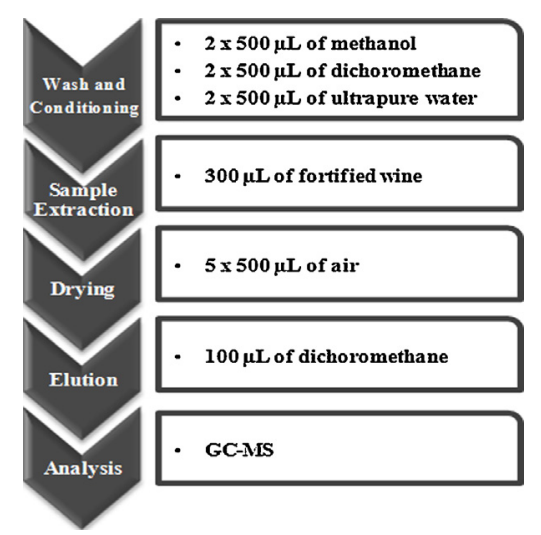

Fig. 1. DoE optimized MEPS procedure for determination of EC in fortified wines.

each extraction, the sorbent was washed and conditioned twice with $500 \mu \mathrm{L}$ of methanol, dichloromethane and ultra-pure water, at about $33 \mu \mathrm{Ls}^{-1}$. Then, $300 \mu \mathrm{L}$ of sample was passed through the sorbent at a flow rate of about $5 \mu \mathrm{Ls}^{-1}$. Thereafter, a drying step was performed passing, five-fold, $500 \mu \mathrm{L}$ of air at $250 \mu \mathrm{Ls}^{-1}$. EC was then eluted with $100 \mu \mathrm{L}$ of dichloromethane, aspirating at $1.7 \mu \mathrm{Ls}^{-1}$ and dispensing at $33 \mu \mathrm{Ls}^{-1}$, approximately. Each sample/standard solution was extracted in triplicate and $3 \mu \mathrm{L}$ of extract was injected twice into the GC-MS port. Each BIN was used for about 120 extractions. The DoE optimized MEPS extraction procedure is schematized in Fig. 1.

\subsection{Method validation}

The described MEPS/GC-MS methodology for determination of EC in fortified wines was validated in terms of linearity, sensitivity, matrix effect, selectivity, precision and accuracy.

The working standard solutions were prepared by spiking both dry and sweet fortified wines at six different concentration levels: $5,10,50,100,200$ and $400 \mu \mathrm{g} \mathrm{L}^{-1}$ of EC with $24 \mu \mathrm{g} \mathrm{L}^{-1}$ of BC as internal standard. Calibration curves were obtained by plotting the analyte peak area ratio (EC area/IS area) from the six increasing standard solutions against the corresponding EC concentration. The linearity $\left(R^{2}\right)$ was determined based on the linear regression results.

Sensitivity was evaluated determining the limit of detection (LOD) and limit of quantification (LOQ) as follows: $L O D=3.3 \sigma / \mathrm{b}$ and $L O Q=10 \sigma / b$, with $\sigma$ as the intercept standard deviation and $b$ the slope.

The matrix effect (ME) was assessed through the percentage of the quotient between the slopes of the curves obtained from the standards solutions in synthetic wine $\left(6 \mathrm{~g} \mathrm{~L}^{-1}\right.$ of tartaric acid, $18 \%$ of ethanol and $\mathrm{pH}$ 3.50) and those obtained by spiking dry and sweet fortified wines with known amounts (matrix-matched calibration) by the following equation [33]:

$$
\% \mathrm{ME}=\left[\frac{\text { Slope of matrix }- \text { matched calibration }- \text { slope of synthetic wine calibration }}{\text { Slope of synthetic wine calibration }}\right] \times 100
$$

Selectivity was appraised by the analysis of several fortified wines, among which were chosen those that were used for the matrixmatched calibration, to ensure the absence of chromatographic interferences, at the retention times of EC and BC (SIM at $m / z 62$ ), which could compromise EC quantification. Synthetic wine blanks were also evaluated.

Precision was estimated from inter-and intra-day analysis of the standard solutions and fortified wines. Intra-day repeatability was assessed by 10 successive replicate determinations of 2 samples and a working standard solution, while inter-day reproducibility

Firstly, $5 \mathrm{~mL}$ of sample/standard solution, previously spiked with $12 \mu \mathrm{L}$ of internal standard (BC solution of $10 \mathrm{mg} \mathrm{L}^{-1}$ ), were filtered through $0.45 \mu \mathrm{m}$ syringe Acrodisc GHP filters (Pall Gelman Sciences, Ann Arbor, MI, USA). Following this step, samples were then extracted using the $\mathrm{C} 8$ sorbent, which was selected to extract EC, after being performed the optimization tests. Before 


\section{Acetonitrile}

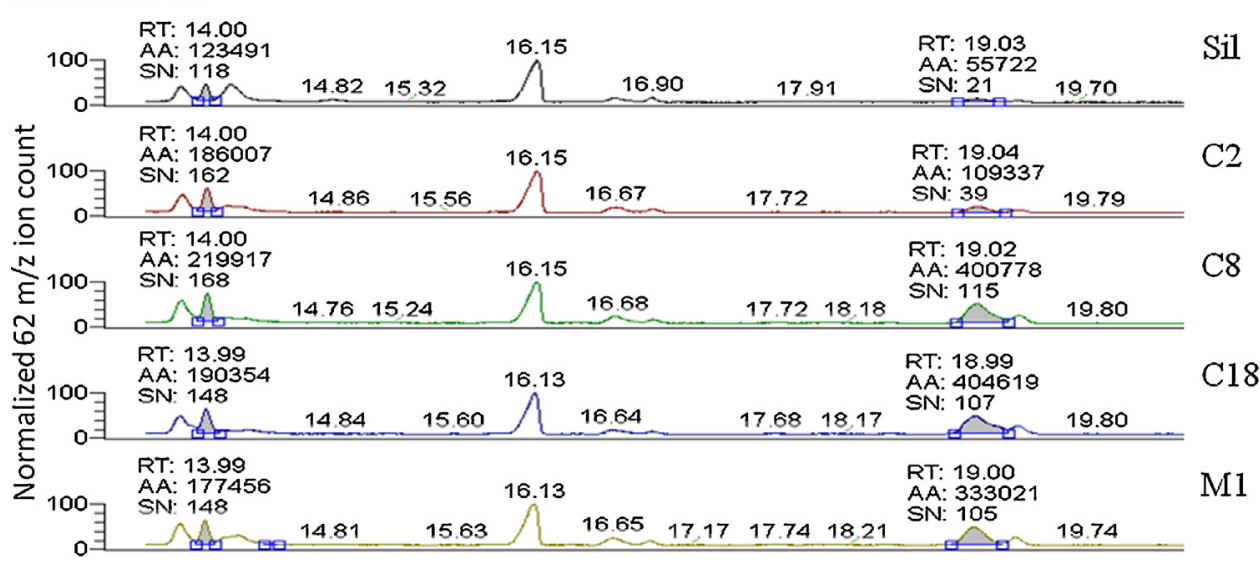

\section{Ethyl acetate}

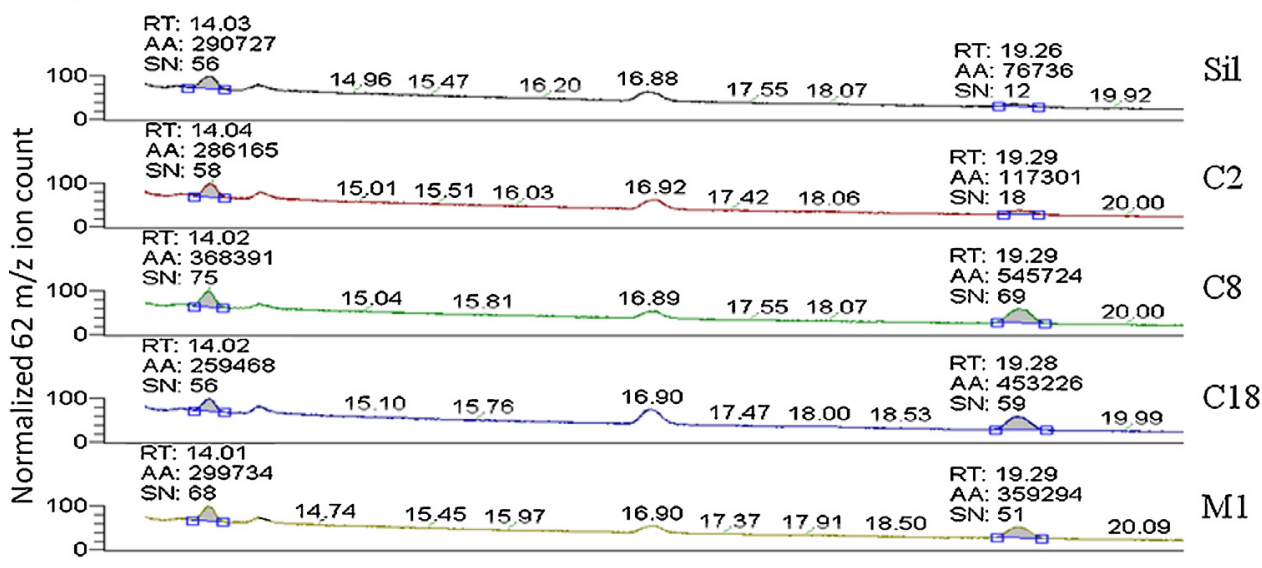

\section{Dichloromethane}

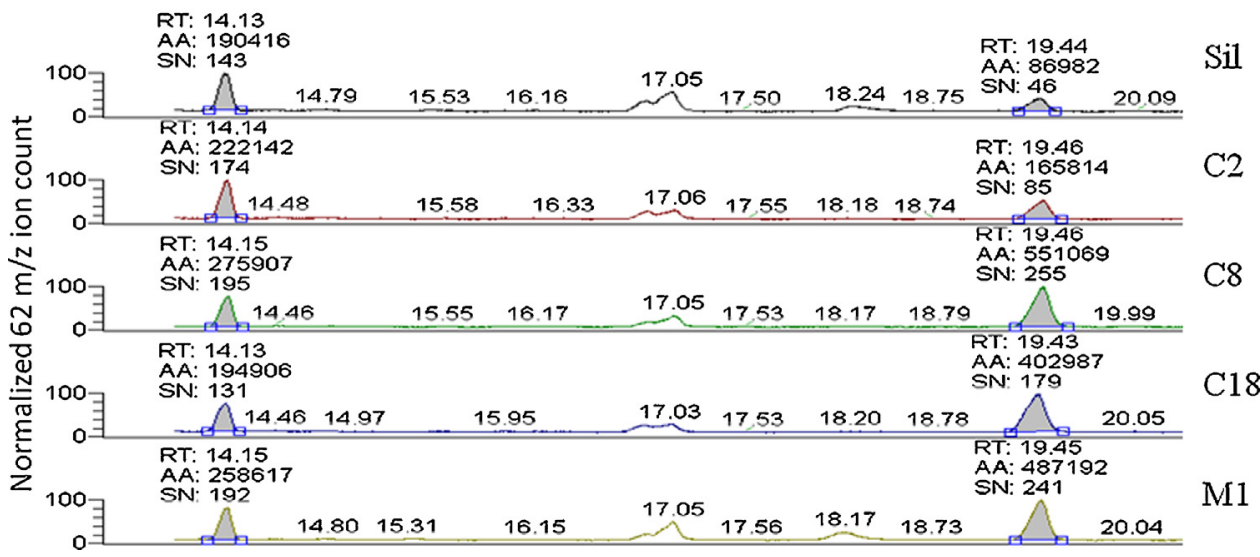

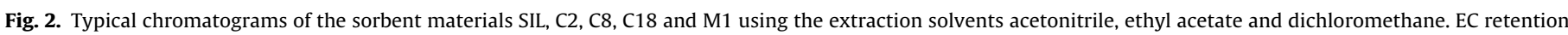
time $\approx 14 \mathrm{~min}, \mathrm{BC}$ retention time $\approx 19 \mathrm{~min}$. RT - retention time; AA - peak area; SN - signal to noise ratio.

was assessed by the analyses of the same samples in 3 different days. These two parameters were expressed as relative standard deviation (\%RSD).

The accuracy of the method was assessed through a recovery study, spiking a fortified wine in triplicate, with known amounts of EC at three representative concentrations levels, within the calibration range. Average recovery was calculated by comparing mean values of the 3 replicates with theoretical concentrations of each one. Carry-over was also investigated by running a blank sample after extracting the working standard solutions with the highest content of EC.

\section{Results and discussion}

Firstly, a concentrated solution of EC, diluted in dichloromethane, was directly injected into the GC-MS and recorded at full scan mode (total ion count) to identify and determine its retention time $\left(t_{R}\right)$. Then, several ramp temperatures were tested in order to optimize the GC-MS analysis of EC. At the same time, to ensure the absence of interfering substances at EC retention time (14.1 min), some non-optimized MEPS extracts of fortified wine samples were analyzed with both TIC and SIM modes. At SIM mode, the analyses were performed recording the 
sum of the three major ions $m / z 62,74$ and 89 and also, only the characteristic ion $\mathrm{m} / \mathrm{z}$ 62. It was found interferences at the EC retention time when the recording was done with the sum of the ions $m / z$ 62, 74 and 89. Indeed, the TIC mode analysis confirmed that the matrix of some fortified wines was very complex and concentrated, compromising the sensitivity. In this sense, it was chosen to perform SIM analysis only at $m / z 62$, which assured enough sensitivity to analyze EC with an excellent performance. Similar strategy has already been adopted by other authors $[18,34,35]$.

\subsection{Extraction solvent survey}

Taking into account the objective of developing an extraction method with MEPS, the potential extraction solvents were analyzed looking for the presence of EC, with the SIM mode at $m / z$ 62 . The obtained results showed that only acetonitrile, ethyl acetate and dichloromethane were EC free solvents. Methanol, ethanol and acetone solvents had measurable amounts of EC, mainly ethanol, which presented the peak with the greatest area of EC.

This result led us to avoid the use of this solvent for calibration purposes, considering that EC presence in ethanol could affect its quantification. Actually, the EC determination in alcoholic beverages presupposes its use to simulate the matrix, since ethanol has direct influence on the EC extraction. Thus, this fact must be taken into account on the development of analytical methods, once standard solutions are currently prepared with a certain percentage of ethanol [25,26,36-38].

Actually, we have tried to find an ethanol source that was absent of EC. In this sense, 3 bottles of ethanol $>99.8 \%$ (GC) of the same brand, available in the laboratory, were tracked through GC-MS direct injection, in order to quantify EC. In this case, the calibration was prepared based on standards diluted in dichloromethane. The resulting calibration showed good linearity and sensitivity results $\left(R^{2}=0.9999\right.$ and $\left.\mathrm{LOQ}=15.21 \mu \mathrm{gL}^{-1}\right)$. The results revealed that ethanol bottles presented concentrations ranging from 25.0 to $27.9 \mu \mathrm{g} \mathrm{L}^{-1}$.

Therefore, the synthetic wine, usually used for the preparation of standards, can have an additional EC concentration of about $4.5 \mu \mathrm{g} \mathrm{L}^{-1}$ derived from the added ethanol (18\%).

\subsection{Selection of the MEPS sorbent and extraction solvent}

After solvents survey, several tests were conducted in order to select the best solvent/sorbent pair. To perform this task, a nonoptimized MEPS procedure was carried out using a $500 \mu \mathrm{L}$ syringe coupled with a hand-held automatic system. This syringe was fitted with a removable BIN containing $4 \mathrm{mg}$ of sorbent material. The performance of the sorbent materials SIL, C2, C8, C18 and M1 were tested with the 3 extraction solvents free of EC. Very recently, new sorbents became commercially available, which could be further tested.

The obtained results were compared to select the best BIN and solvent to extract and quantify EC in fortified wines. Regarding the extraction solvent, it was verified that acetonitrile extracts less EC compared to the other two extraction solvents, regardless the BIN used. Moreover, acetonitrile extracted some interfering substances that co-eluted with the EC and BC peaks (Fig. 2). In turn, ethyl acetate and dichloromethane were the solvents with higher efficiency in the extraction of EC and BC. Actually, ethyl acetate extracts more EC than dichloromethane, however, causes a change in the baseline, reducing the signal to noise ratio $\left(\mathrm{SN}^{-1}\right)$ of both $\mathrm{EC}$ and $\mathrm{BC}$ peaks (Fig. 2). Furthermore, the EC peak of the ethyl acetate extracts presented an inferior resolution, as depicted in Fig. 2. Considering these results, dichloromethane was chosen as extraction solvent.

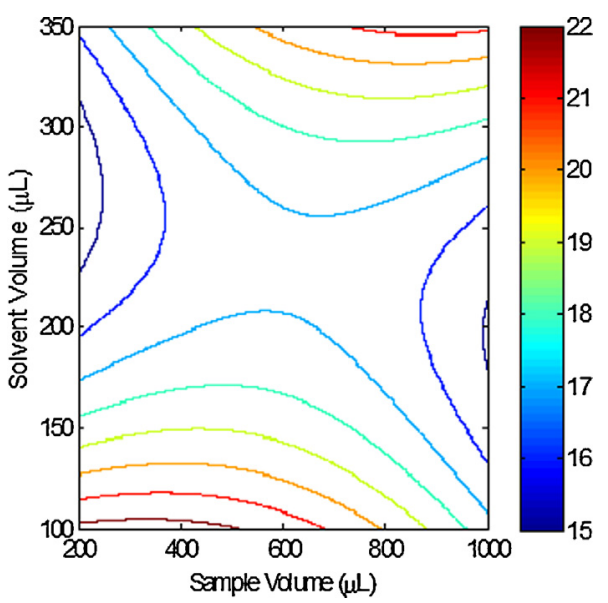

Fig. 3. DoE to optimize the MEPS extraction with C8 BIN with sample volume, extraction solvent volume and the response in GC-MS equipment as variables. The colormap illustrates the variation of GC-MS response, where the maximum is delimited by the dark red line (solvent volume up to $100 \mu \mathrm{L}$ and sample volume range of 200-500 $\mu \mathrm{L}$ ). (For interpretation of the references to color in this figure legend, the reader is referred to the web version of the article.)

The BIN with C8 sorbent material presented the best efficiency to extract EC (Fig. 2), using dichloromethane as extraction solvent. Thus, C8 BIN and dichloromethane were chosen to perform the MEPS/GC-MS methodology for the determination of EC in fortified wines.

\subsection{MEPS extraction optimization}

After choosing the $\mathrm{C} 8$ /dichloromethane pair, an experimental design (DoE) was carried out to optimize the extraction in order to obtain the best response in the GC-MS equipment. The sample and extraction solvent volumes were the chosen variables. The sample volumes analyzed were 200,500 and $1000 \mu \mathrm{L}$, while the tested solvent volumes were 100, 200 and $350 \mu$ L. Fig. 3 depicts the result of the statistical DoE approach. The two factors analyzed were plotted against the response variable in order to visualize the combination that maximizes the GC-MS response. Moreover, the response of other interferences was also analyzed in order to ensure that the chosen factors combination maximize the $\mathrm{S} \mathrm{N}^{-1}$ of the methodology used.

The optimum conditions were achieved by maximizing the second order function, which has sample and solvent volume as dependent variables and GC response as independent variable. As illustrated by Fig. 3, the maximum EC peak area can be achieved by using $100 \mu \mathrm{L}$ of dichloromethane and $300 \mu \mathrm{L}$ of wine sample. Other conditions that also affect the MEPS extraction, such as aspiration/dispense rates and conditioning/equilibration steps, were adjusted (Section 2.4) taking into account the tips reported by previous methods, ensuring efficiency and effectiveness [39,40].

\subsection{Matrix effects}

The matrix effect can compromise the results generated by an analytical method, especially when it is intended to analyze samples of high complexity, such as fortified wines. Thus, the variation percentages of the slopes of three calibration curves, accessed with synthetic, dry and sweet fortified wines as samples matrix and using the optimized extraction, were compared to evaluate the matrix influence on the extraction procedure and analysis.

Although there is no limit values established for matrix effect, it can be considered that up to $15 \%$ of matrix suppression or enhancement is acceptable. In the present study a value of $17 \%$ was obtained, revealing a small matrix effect when wines were used instead 


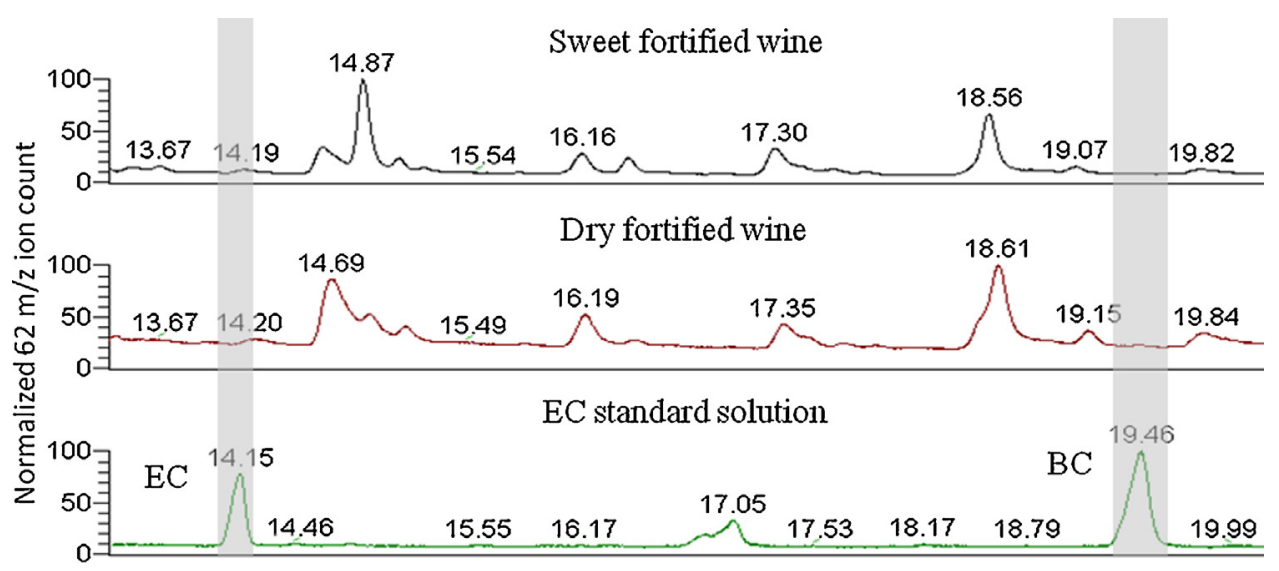

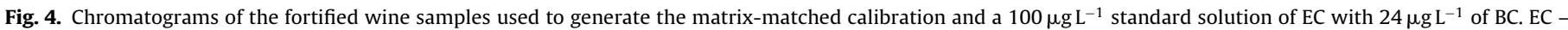
ethyl carbamate; $\mathrm{BC}$ - butyl carbamate.

of synthetic wine. A negligible difference was found (about $0.3 \%$ ) between the two types of wines.

\subsection{Method validation}

Faced with the lack of an ethanol completely free of EC, together with the fact that was observed matrix effect, it was decided to adopt the matrix-matched calibration approach to overcome these drawbacks. To accomplish this calibration, the selectivity of the proposed methodology was firstly assessed by the analysis of the sweet and dry fortified wines, which were further used to generate the matrix-matched calibration. The results revealed that there were no significant interferences at EC and BC retention times, $14.1 \mathrm{~min}$ and $19.4 \mathrm{~min}$, respectively, as demonstrated in Fig. 4.

A single calibration curve was then obtained by the average response of the six concentration levels prepared with both sweet and dry fortified wine standard solutions. Each one was extracted in triplicate and injected in duplicate. A good correlation coefficient $\left(R^{2}=0.9999\right)$ was observed, confirming the linearity of the method. Table 1 depicts some of the validation results.

The method sensitivity was evaluated by LOD and LOQ determinations, calculated based on the obtained linear regression (Section 2.5). The LOD and LOQ were low $\left(1.5 \mu \mathrm{g} \mathrm{L}^{-1}\right.$ and $4.5 \mu \mathrm{g} \mathrm{L}^{-1}$, respectively), being close or even lower to those found in literatures $[3,13,15,18,19,24-26,34,35,37,41]$, conferring to the developed methodology a great sensitivity to analyze EC in fortified wines.

Recovery study was carried out to determine the accuracy of the method, by spiking a fortified wine with known amounts of EC, at three concentration levels representative of the calibration range. The wine sample was analyzed before and after the

Table 1

Validation results obtained for the proposed MEPS/GC-MS methodology.

\begin{tabular}{|c|c|c|}
\hline Parameter & & Result \\
\hline Linear regression $(y=m x+b)$ & & $0.01045 x+0.13741$ \\
\hline Linear concentration range & & $5-400 \mu \mathrm{g} \mathrm{L}^{-1}$ \\
\hline$R^{2}$ & & 0.9999 \\
\hline $\operatorname{LOD}\left(\mu \mathrm{gL}^{-1}\right)$ & & 1.5 \\
\hline $\mathrm{LOQ}\left(\mu \mathrm{g} \mathrm{L}^{-1}\right)$ & & 4.5 \\
\hline Recovery & $\mathrm{Cc} \pm \mathrm{SD}\left(\mu \mathrm{g} \mathrm{L}^{-1}\right)$ & $\%$ \\
\hline FW & $26 \pm 2$ & - \\
\hline $\mathrm{FW}+\mathrm{EC} 50 \mu \mathrm{g} \mathrm{L}^{-1}$ & $78 \pm 4$ & 106 \\
\hline $\mathrm{FW}+\mathrm{EC} 100 \mu \mathrm{g} \mathrm{L}^{-1}$ & $123 \pm 6$ & 97 \\
\hline $\mathrm{FW}+\mathrm{EC} 200 \mu \mathrm{g} \mathrm{L}^{-1}$ & $228 \pm 10$ & 101 \\
\hline
\end{tabular}

LOD, limit of detection; LOQ, limit of quantification; Cc, concentration; FW, fortified wine; SD, standard deviation. addition of 3 different amounts of EC. The recoveries ranged between $97 \%$ and $106 \%$, demonstrating the good accuracy of the developed methodology (Table 1).

The method precision (repeatability and reproducibility) was evaluated by the variation of intra- and inter-day (three different days with an interval of 5 days between them) repetition method. Repeatability was accessed by 5 successive extractions injected twice of $100 \mu \mathrm{g} \mathrm{L}^{-1}$ standard solution and 2 fortified wines, with different concentrations. The reproducibility was estimated by the variation between the intra-day results and those obtained in inter-day analyses, through the extraction (triplicate) and injection (duplicate) of the same 3 samples. The results revealed a good repeatability (5-7\%) and reproducibility (4-7\%) of the methodology, since all RSD values were lower than $7 \%$, regardless the area and height of the EC peak.

Additionally, the analysis of blanks after extracting the standard solutions with the highest content of EC, confirmed the absence of carry-over between extractions.

\subsection{Analysis of fortified wine samples}

To evaluate the applicability of the proposed MEPS/GC-MS methodology for determination of EC in fortified wines a set of fortified wines, aged up to 36 years old, were analyzed. All samples were extracted in triplicate and injected twice. The results are shown in Table 2. The older wines were analyzed in order to check

Table 2

Application of the proposed methodology for the EC quantification of 16 fortified wines.

\begin{tabular}{llcl}
\hline & Wine age (years) & Concentration $\left(\mu \mathrm{gL}^{-1}\right)$ & $\mathrm{SD}(n=6)$ \\
\hline $\mathrm{FW}_{1}$ & 5 & 28 & 3 \\
$\mathrm{FW}_{2}$ & 5 & 31 & 3 \\
$\mathrm{FW}_{3}$ & 5 & 22 & 4 \\
$\mathrm{FW}_{4}$ & 3 & 18 & 2 \\
$\mathrm{FW}_{5}$ & 5 & 38 & 2 \\
$\mathrm{FW}_{6}$ & 3 & 50 & 2 \\
$\mathrm{FW}_{7}$ & 5 & 13 & 2 \\
$\mathrm{FW}_{8}$ & unk & 7.6 & 0.1 \\
$\mathrm{FW}_{9}$ & 17 & 76.1 & 0.7 \\
$\mathrm{FW}_{10}$ & 16 & 85.5 & 0.9 \\
$\mathrm{FW}_{11}$ & 36 & 132 & 5 \\
$\mathrm{FW}_{12}$ & 18 & 138 & 5 \\
$\mathrm{FW}_{13}$ & 18 & 107 & 3 \\
$\mathrm{FW}_{14}$ & 17 & 93 & 3 \\
$\mathrm{FW}_{15}$ & 25 & 206 & 7 \\
FW $_{16}$ & unk & 7.3 & 0.3 \\
\hline
\end{tabular}

FW, fortified wine; unk, unknown; SD, standard deviation. 
the adopted linear range, as EC content is expected to increase with age [2].

The obtained chromatograms showed that the applicability of the MEPS/GC-MS methodology to quantify EC in fortified wines was achieved, since they showed a good peak resolution, confirming its selectivity. Additionally, the quantified concentrations varied from 7.3 to $206 \mu \mathrm{g} \mathrm{L}^{-1}$, showing that the developed methodology covers the range interest of the compound (Table 2). Actually, the fact that wines with higher content of EC were in general associated with higher aging periods was also demonstrated.

\section{Conclusion}

A fast, simple and sensitive methodology was developed and optimized to quantify EC in fortified wines using MEPS extraction, through a hand-held automated analytical syringe, with GC-MS detection. The best solvent/sorbent pair was selected after testing several sorbent materials and EC free extraction solvents. C8 BIN and dichloromethane were the most efficient pair to extract EC. MEPS extraction was optimized performing an experimental design, varying sample and extraction solvent volumes. The best response could be achieved with the passage of $300 \mu \mathrm{L}$ of sample and $100 \mu \mathrm{L}$ of dichloromethane.

The matrix effect study revealed that a noticeable effect of both sweet and dry fortified wines exists relative to synthetic wine. In turn, and together with the fact that it was not found an ethanol completely free of EC commercially available, a matrix-matched calibration was performed using both sweet and dry fortified wines. The analytical methodology was then validated, showing good results in terms of linearity, sensitivity, selectivity precision and accuracy. The applicability of the methodology was demonstrated by the analysis of a set of 16 fortified wines, with values ranging between 7.3 and $206 \mu \mathrm{gL}^{-1}$. The corresponding chromatograms showed good precision and resolution.

Finally, it can be concluded that the presented MEPS/GC-MS methodology is an excellent tool to quantify EC in fortified wines, gathering efficiency and effectiveness, without using long and hard-working procedures, like the conventional methodology adopted by the OIV.

\section{Acknowledgment}

The authors acknowledge the FEDER (Intervir+ program) for the financial support of VALIMED project.

\section{References}

[1] R. Baan, K. Straif, Y. Grosse, B. Secretan, F. El Ghissassi, V. Bouvard, A. Altieri, V. Cogliano, The Lancet Oncology 8 (2007) 292.

[2] S. Hasnip, A. Caputi, C. Crews, P. Brereton, Food Additives \& Contaminants 21 (2004) 1155.

[3] M.J. Dennis, N. Howarth, P.E. Key, M. Pointer, R.C. Massey, Food Additives \& Contaminants 6 (1989) 383.

[4] M. Vahl, Food Additives \& Contaminants 10 (1993) 585.
[5] F.A. Beland, R.W. Benson, P.W. Mellick, R.M. Kovatch, D.W. Roberts, J.-L. Fang, D.R. Doerge, Food and Chemical Toxicology 43 (2005) 1.

[6] J.V. Weber, V.I. Sharypov, Environmental Chemistry Letters 7 (2009) 233.

[7] D. Wang, B. Yang, X. Zhai, L. Zhou, Fuel Processing Technology 88 (2007) 807.

[8] D.F. Stevens, C.S. Ough, American Journal of Enology and Viticulture 44 (1993) 309.

[9] M.E. Arena, F.M. Saguir, M.C. Manca de Nadra, International Journal of Food Microbiology 52 (1999) 155.

[10] T.K. Franks, Y. Hayasaka, S. Choimes, R. van Heeswijck, Phytochemistry 66 (2005) 165.

[11] V.O. Aina, B. Sambo, A. Zakari, H.M.S. Hauwa, H. Umar, R.M. Akinboboye, A Mohammed, Advance Journal of Food Science and Technology 4 (2012) 445.

[12] EFSA, Opinion of the Scientific Panel on Contaminants in the Food chain on a request from the European Commission on ethyl carbamate and hydrocyanic acid in food and beverages, EFSA Journal 551 (2007) 1.

[13] C. Fauhl, R. Wittkowski, Journal of High Resolution Chromatography 15 (1992) 203.

[14] P. Herbert, L. Santos, M. Bastos, P. Barros, A. Alves, Journal of Food Science 67 (2002) 1616.

[15] X. Xu, Y. Gao, X. Cao, X. Wang, G. Song, J. Zhao, Y. Hu, Journal of Separation Science 35 (2012) 804

[16] B.J. Canas, F.L. Joe, G.W. Diachenko, G. Burns, Journal of AOAC International 77 (1994) 1530.

[17] OIV, Ethyl Carbamate, OIV-MA-AS315-04, Compendium of international methods of analysis 2 (2013) 25.

[18] E. Jagerdeo, S. Dugar, G.D. Foster, H. Schenck, Journal of Agricultural and Food Chemistry 50 (2002) 5797.

[19] P. Alberts, M.A. Stander, A. De Villiers, Food Additives \& Contaminants: Part A 28 (2011) 826.

[20] Y.-P. Ma, F.-Q. Deng, D.-Z. Chen, S.-W. Sun, Journal of Chromatography A 695 (1995) 259.

[21] H. Kwon-Pyo, K. Yoon-Seok, J. Dong-Chae, P. Sae-Rom, Y. Ji-Ho, L. Sung-Yong, K. Yong Seok, K. So Hee, H. Sang-Do, P. Sang Kyu, B. Dong-Ho, Food Science and Biotechnology 16 (2007) 975.

[22] D.W. Lachenmeier, W. Frank, T. Kuballa, Rapid Communications in Mass Spectrometry 19 (2005) 108.

[23] S.-C. Chung, K. Kwong, B.-S. Chen, Chroma 72 (2010) 571.

[24] R.S. Whiton, B.W. Zoecklein, American Journal of Enology and Viticulture 53 (2002) 60.

[25] R. Perestrelo, S. Petronilho, J.S. Câmara, S.M. Rocha, Journal of Chromatography A 1217 (2010) 3441.

[26] D.W. Lachenmeier, U. Nerlich, T. Kuballa, Journal of Chromatography A 1108 (2006) 116.

[27] Q. Liao, W. Li, L. Luo, Analytical and Bioanalytical Chemistry 405 (2013) 6791.

[28] M. Abdel-Rehim, Journal of Chromatography A 1217 (2010) 2569.

[29] M. Adam, P. Pavlíková, A. Čížková, P. Bajerová, K. Ventura, Food Chemistry 135 (2012) 1613.

[30] J. Gonçalves, C.L. Silva, P.C. Castilho, J.S. Câmara, Microchemical Journal 106 (2013) 129

[31] S. Jönsson, J. Hagberg, B. van Bavel, Journal of Agricultural and Food Chemistry 56 (2008) 4962.

[32] D.C. Montgomery, Design and Analysis of Experiments, Wiley, New York, 2006

[33] B.K. Matuszewski, M.L. Constanzer, C.M. Chavez-Eng, Analytical Chemistry 75 (2003) 3019.

[34] C.A. Uthurry, F. Varela, B. Colomo, J.A. Suárez Lepe, J. Lombardero, J.R. García del Hierro, Food Chemistry 88 (2004) 329.

[35] I.S. Woo, I.H. Kim, U.J. Yun, S.K. Chung, I.K. Rhee, S.W. Choi, H.D. Park, Journal of Industrial Microbiology and Biotechnology 26 (2001) 363.

[36] S.N.F. Bruno, D.S. Vaitsman, C.N. Kunigami, M.G. Brasil, Food Chemistry 104 (2007) 1345.

[37] Z. Ajtony, N. Szoboszlai, L. Bencs, E. Viszket, V.G. Mihucz, Food Chemistry 141 (2013) 1301.

[38] R.R. Madrera, B.S. Valles, Food Control 20 (2009) 139.

[39] C. García Pinto, A. Pérez Antón, J.L. Pérez Pavón, B. Moreno Cordero, Journal of Chromatography A 1260 (2012) 200.

[40] H. Vlčková, M. Rabatinová, A. Mikšová, G. Kolouchová, S. Mičuda, P. Solich, L. Nováková, Talanta 90 (2012) 22.

[41] C. Fauhl, R. Catsburg, R. Wittkowski, Food Chemistry 48 (1993) 313. 